Bangladesh J. Bot. 44(3): 415-421, 2015 (September)

\title{
USE OF ANTIGENIC COMPOSITION TO DIFFERENTIATE AMONG RHIZOCTONIA SOLANI ISOLATES FROM FLAX
}

\author{
EM Hussein, AA Aly, Ola Gh el-Hawary, Heba I Mohamed ${ }^{* 1}$, \\ AA Mosa ${ }^{2}$ AND MH Mostafa \\ Plant Pathology Research Institute, Agricultural Research Center, Giza, Egypt
}

Key words: Antigenic composition, Rhizoctonia solani, Flax, Serology

\begin{abstract}
Rhizoctonia solani is an plant pathogenic fungus with a wide host range and worldwide distribution. Double diffusion technique was used to differentiate among Rhizoctonia solani isolates from flax. In this technique, antisera of isolate 23 (AG-2) and isolate 24 (AG-4) reacted against antigens of 24 isolates belonging to AG-2 and Ag-4. The antiserum of isolate 23 (AG-2) was insensitive to differentiate among the isolates of AG-2, while it was highly sensitive to differentiate among some isolates of AG-4. The antiserum of isolate 24 (AG-4) was highly sensitive as a serotaxonomic tool to differentiate among AG-2 and AG-4, while it was of limited value in differentiating among isolates of within each AG.
\end{abstract}

\section{Introduction}

Rhizoctonia solani Kühn (teleomorph: Thanatephorum cucumeris (Frank) Donk) is one of the most primitive Basidiomycetes. Rhizoctonia solani exists in its vegetative form in nearly all agricultural soils. In this non-spore-producing phase, the fungus lives saprophytically on dead plant remains, but it can become vigorously parasitic when roots or other parts of a susceptible host penetrate the infested zone (Watkins 1981).

Rhizoctonia solani attacks flax at early stage of development, destroying the root and causing thinning or in severe infection, death of seedling (Krylova 1981). The fungus also causes root rot symptoms, which appear in plants after the flowering stage (Hartman 1996).

Current classification of $R$. solani is based largely on grouping of isolates into anastomosis groups $\left(\mathrm{AG}_{\mathrm{s}}\right)$. Anastomosis, or the fusion of hyphae between different individuals, may result in the sharing of genetic material without sexual reproduction, but it also serves to isolate individuals from other members of the same species that do not share the same alleles for somatic compatibility (Agrios 2005).

Serology is one of the biochemical techniques, which are proposed as being useful in fungal taxonomy; however, there are few papers in the literature reporting the serological separation of fungal isolates by using double diffusion (DD) technique. For example, (Abe et al. 1969) reported that antisera developed against an isolate of $R$. solani causing root rot of sugar beet reacted strongly with other isolates of that fungus, showing four precipitin bands. Thus, it was concluded that pathogenic isolates associated within a particular disease have the same serological characteristics. (Adams and Butler 1979) studied six $\mathrm{AG}_{\mathrm{s}}$ of $R$. solani and found that $\mathrm{AG}_{\mathrm{s}}$ obtained from microscopic technique corresponded to identified serological groups. Ag2-1 and AG2-2 were serologically indistinguishable. (Hussein et al. 1996) compared Fusarium oxysporum, F. moniliforme, and $F$. solani isolates by DD technique to determine their serological relationships. The taxonomic relationships established based on DD matched those based on modern systems of morphological classification.

*Author for correspondence: <hebaibrahim79@yahoo.com>. ${ }^{1}$ Department of Biological and Geological Science, Faculty of Education, Ain Shams University, Cairo, Egypt. ${ }^{2}$ Department of Plant Pathology, Faculty of Agriculture, Ain Shams University, Cairo, Egypt. 
Each of T. longbrachiatum and T. harzianum isolates tended to group together based on their antigenic composition, which indicated a remarkable overall serological similarity among isolates of each species. However, the serological differences among the isolates did not always reflect the taxonomic differences because some isolates of $T$. longbrachiatum and T. harzianum showed considerable serological similarity.

The present investigation was initiated to determine whether $\mathrm{AG}_{\mathrm{s}}$ obtained from microscopic examination of $R$. solani isolates from flax correspond to serological grouping of these isolates by using DD technique. The antigenic relationships among isolates within $\mathrm{AG}_{\mathrm{s}}$ were also evaluated.

\section{Materials and Methods}

The isolates of Rhizoctonia solani were originally recovered from flax (Linum usitatismum L.) seedlings. The fungal isolates used in the present study were obtained from the fungal collection of Cotton and Fiber Crops Diseases Research Section, Plant Pathology Research Institute, Agricultural Research Center, Giza, Egypt.

Antigens were prepared according to the method described by Guseva and Gromova (1982), Rataj-Guranowska et al. (1984), and Hussein (1992). Antigens for immunization of rabbits were prepared from mycelium grown for 8 days at $20-30^{\circ} \mathrm{C}$ on liquid Czapeck's medium. The mycelium was harvested by filtration through cheese cloth, washed with distilled water several times, and freeze-dried. This frozen mycelium was suspended on phosphate buffer $\mathrm{pH} 8.3$ (1-3 $\mathrm{ml} / \mathrm{g}$ mycelium), mixed thoroughly with glass beads and ground in liquid nitrogen to a fine powder. The ground mycelium was centrifuged at $19,000 \mathrm{rpm}$ for $30 \mathrm{~min}$. at $0^{\circ} \mathrm{C}$. The protein content in supernatant was estimated according to Bradford (1976) by using bovine serum albumin as a standard protein. If protein concentration was low, protein would be precipitated from the clarified supernatant by adding ammonium sulphate at $70 \%$ of saturation $(60 \mathrm{~g} / 100 \mathrm{ml})$ then kept in the refrigerator for $30 \mathrm{hrs}$. Pellets, collected by centrifugation at 11,000 rpm for $30 \mathrm{~min}$., were re-suspended in phosphate buffer $\mathrm{pH} 8.3$ and subjected to dialysis for $24 \mathrm{hrs}$ against the buffer and centrifugation at 11,000 rpm for $30 \mathrm{~min}$. Protein was estimated in the obtained supernatant.

New Zealand rabbits, $3-4 \mathrm{~kg}$ weight, were immunized by antigens of isolates nos. 23 (R. solani AG-2) and 24 (R. solani AG-4) to produce antisera. The first injection was given intraacutaneously in the back between ears. This injection consisted of $0.5 \mathrm{mg}$ protein suspended in 1 $\mathrm{ml} /$ phosphate buffer and mixed in $1 \mathrm{ml}$ Freund's complete adjuvant. After one week, each animal was received $4 \mathrm{ml}$ protein administered intramuscularly every third day in the thigh in a series of twelve injections. One week after the last injection, the animals were bled and antibodies in serum were assayed by double diffusion technique.

The technique was carried out according to Ouchterlony and Nilsson (1978). One per cent agrose, melted in saline and supplemented with merthiolate $(1: 10,000)$, was poured into $9 \mathrm{~cm}$ diameter Petri dishes to obtain a layer of agar $1-2 \mathrm{~mm}$ thick. The diameter of the central and of the 4 peripheral wells, were 5 and $3 \mathrm{~mm}$, respectively. The distance between the central well and the peripheral ones was $15 \mathrm{~mm}$. The central well was filled with antiserum and the peripheral wells with antigens. Dishes were kept in humid conditions at room temperature $\left(18-24^{\circ} \mathrm{C}\right)$ in the dark for one week. The developing precipitin lines were examined and recorded by hand drawing.

Simple matching coefficient (SSM) was calculated for each pair of isolates (Sokal and Michner 1958). Based on these data, a similarity matrix (not shown) was constructed and from this matrix, isolates were clustered by the average linked technique (unweighted pair-group method). The results were expressed as phenogram (Joseph et al. 1992). Cluster analysis was performed with the SPSS 6.0 software package. 


\section{Results and Discussion}

Several isolates used in the present study were listed in Table (1). Double diffusion (DD) technique was used to differentiate among $R$. solani isolates. The reactions of the antiserum of isolate 23 (AG-2) against antigens of 24 isolates belonging to AG-2 and AG-4 are shown in Table 2. Fig. 1 showed the phenogram constructed based on taxonomic distances $\left(\mathrm{TD}_{\mathrm{s}}\right)$ generated from cluster analysis of the data shown in Table 2. In this phenogram, the smaller the TD, the more closely the isolates were related in their antigenic composition. The phenogram was divided into 4 subclusters. The first subcluster $(\mathrm{TD}=8)$ included all the isolates of AG-2 and only two isolates of AG-4, that is, $77.78 \%$ of the isolates in this subcluster belonged to AG-2. Isolates of this subcluster, except isolate 13, were identical in their antigenic composition. The remaining isolates of AG-4 (15 isolates) were distributed over 3 subclusters at $\mathrm{TD}_{\mathrm{s}} 7,10.5$, and 18 . Based on the phenogram of Fig. 1, it seems reasonable to concluded that the antiserum of isolate 23 (AG-2) was

Table 1. Isolates of Rhizoctonia solani from flax seedling.

\begin{tabular}{cccl}
\hline Isolate no. & Geographic origin & Anastomosis group & Previous crop \\
\hline 1 & Kafr El-Sheikh & AG-4 & Rice \\
2 & $"$ & AG-4 & Cotton \\
3 & $"$ & AG-2 & Corn \\
4 & $"$ & AG-4 & Rice \\
5 & $"$ & AG-4 & Cotton \\
6 & $"$ & AG-4 & Rice \\
7 & $"$ & AG-4 & $"$ \\
8 & $"$ & AG-2 & Cotton \\
9 & $"$ & AG-4 & Corn \\
10 & Damiatta & AG-4 & $"$ \\
11 & $"$ & AG-2 & $"$ \\
12 & $"$ & AG-4 & Cotton \\
13 & $"$ & AG-4 & Corn \\
14 & $"$ & AG-4 & Rice \\
15 & $"$ & AG-4 & Cotton \\
16 & $"$ & AG-4 & Corn \\
17 & $"$ & AG-2 & $"$ \\
18 & $"$ & AG-2 & $"$ \\
19 & Gharbiya & AG-4 & Rice \\
20 & $"$ & AG-4 & Corn \\
21 & $"$ & AG-4 & Rice \\
22 & $"$ & AG-2 & $"$ \\
23 & $"$ & AG-4 & Cotton \\
24 & $"$ & AG-2 & Corn \\
\hline
\end{tabular}

insensitive to differentiate among the isolates of AG-2, while it was highly sensitive to differentiate among some isolates of AG-4. For example, isolates 4 and 6 or isolates 3 and 7 of AG-4 were easily distinguished by their antigenic composition. Thus, members of each pair of isolates were placed in two remotely related subclusters. In practical terms, the observed isolate specific antigenic compositions may be useful as biochemical markers in ecological studies in soil 
where "marked" isolates are needed. The specific antigenic composition of isolates would facilitate their identification after reisolation from soil.

Table 2. Number and distribution of protein fractions obtained by double-diffusion reaction of antiserum of $R$. solani isolate no. 23 (AG-2) against antigens of $R$. solani isolates from flax.

\begin{tabular}{|c|c|c|c|c|c|c|}
\hline \multirow{2}{*}{$\begin{array}{l}\text { Antiserum of isolate }{ }^{\mathrm{a}} \text { no. } 23 \mathrm{x} \\
\text { antigens of isolate no. }\end{array}$} & \multicolumn{6}{|c|}{ Distance $(\mathrm{mm})$ of protein fraction ${ }^{b}$} \\
\hline & 1 & 2 & 3 & 4 & 5 & 6 \\
\hline 1 & ${ }^{c}+$ & + & - & - & + & - \\
\hline 2 & + & + & - & - & + & - \\
\hline 3 & + & + & - & - & + & - \\
\hline 4 & + & - & + & - & + & - \\
\hline 5 & + & - & + & - & + & - \\
\hline 6 & + & + & + & - & - & + \\
\hline 7 & - & - & + & - & - & + \\
\hline 8 & + & - & + & - & + & - \\
\hline 9 & - & + & + & - & + & - \\
\hline 10 & + & + & - & - & + & - \\
\hline 11 & - & + & - & - & + & - \\
\hline 12 & + & - & + & - & + & - \\
\hline 13 & - & - & + & - & + & - \\
\hline 14 & + & - & + & - & + & - \\
\hline 15 & - & + & + & - & + & - \\
\hline 16 & + & + & - & - & + & - \\
\hline 17 & + & + & + & - & + & - \\
\hline 18 & - & + & - & - & + & - \\
\hline 19 & + & - & + & - & + & - \\
\hline 20 & - & + & + & - & + & - \\
\hline 21 & + & - & + & - & + & - \\
\hline 22 & + & + & + & - & + & - \\
\hline $23^{*}$ & + & - & + & - & + & - \\
\hline 24 & + & + & + & + & + & - \\
\hline
\end{tabular}

${ }^{\mathrm{a}}$ Isolates nos. 1, 2, 3, 4, 6, 7, 9, 10, 11, 15, 16, 17, 18, 20, 21, 22, and 24 were Ag-4, while isolates no s. $_{\text {. 5, 8, }}$ $12,13,14,19$, and 24 were AG-2. ${ }^{b}$ Migration distance of the protein fraction from the central well, which contained the antiserum. ${ }^{c}$ Protein fraction was present (+) or absent (-). *Homologous reaction.

Double diffusion reactions of the antiserum of isolate 24 (AG-4) against antigens of 24 isolates of AG-2 and AG-4 are shown in Table 3. Fig. 2 showed a phenogram constructed based on $\mathrm{TD}_{\mathrm{s}}$ generated from cluster analysis of the data shown in Table 3 . The phenogram composed of two distinct unrelated subclusters. The first one $(\mathrm{TD}=7)$ included all isolates of AG-4, while the second one $(\mathrm{TD}=18)$ included all isolates of AG-2. Isolates of AG-4 in the first subcluster, except isolates 9 and 7, were identical in their antigenic composition $(\mathrm{TD}=0.00)$. On the other hand, isolates of AG-2 tended to be heterogeneous in their antigenic composition. The phenogram proved that the antiserum of isolate 24 (AG-4) was highly sensitive as a serotaxonomic tool to differentiate among AG-2 and AG-4, while it was of limited value in differentiating among the isolates within each AG. 


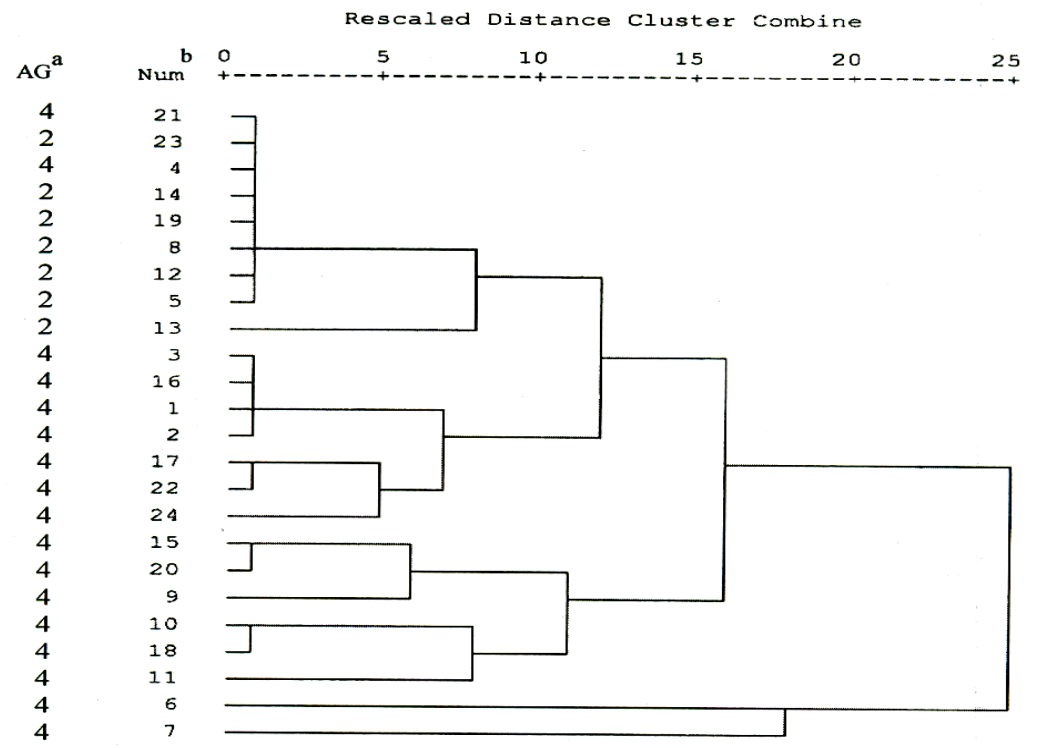

Fig. 1. Phenogram based on average linkage cluster analysis of serological protein patterns obtained by double diffusion technique from 24 isolates of Rhizoctonia solani when their antigens interacted against antiserum of isolate no. 23 (AG-2) from flax. ${ }^{a}$ Anastomosis group of isolate. ${ }^{b}$ Isolate number.

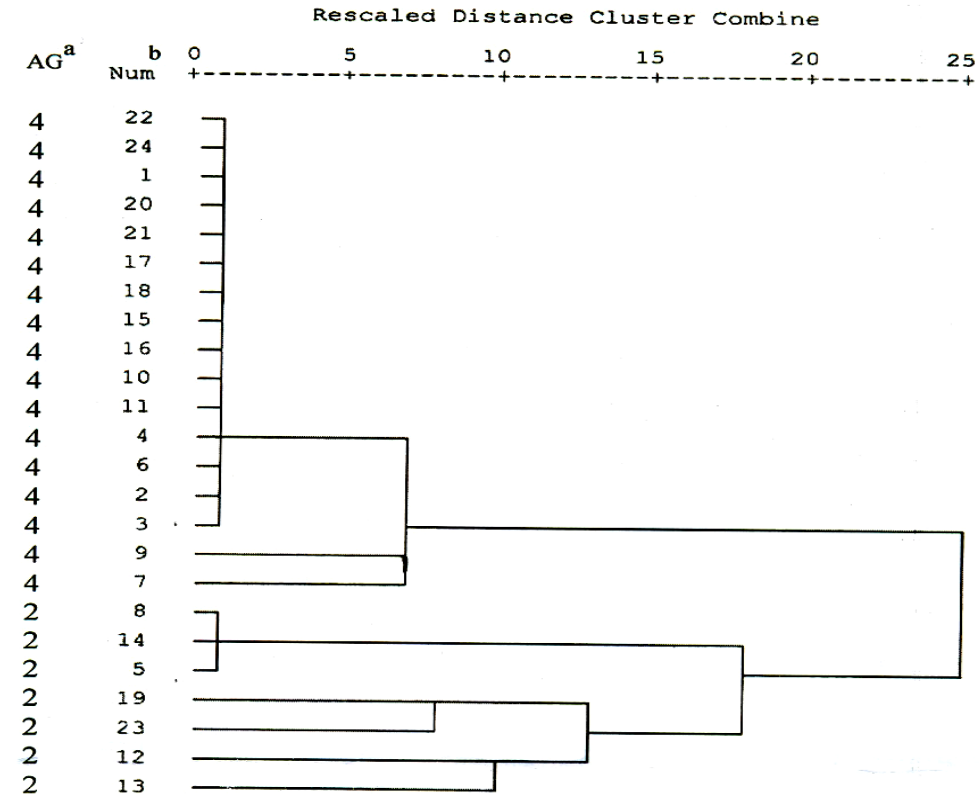

Fig. 2. Phenogram based on average linkage cluster analysis of serological protein patterns obtained by double diffusion technique from 24 isolates of Rhizoctonia solani when their antigens interacted against antiserum of isolate no. 24 (AG-4) from flax. ${ }^{a}$ Anastomosis group of isolate. ${ }^{\mathrm{b}}$ Isolate number. 
Table 3. Number and distribution of protein fractions obtained by double-diffusion reaction of antiserum of $R$. solani isolate no. 24 (AG-4) against antigens of $R$. solani isolates from flax.

\begin{tabular}{|c|c|c|c|c|c|c|c|c|}
\hline \multirow{2}{*}{$\begin{array}{l}\text { Antiserum of isolate }{ }^{a} \text { no. } 24 x \\
\text { antigens of isolate no. }\end{array}$} & \multicolumn{8}{|c|}{ Distance $(\mathrm{mm})$ of protein fraction ${ }^{b}$} \\
\hline & 1 & 2 & 3 & 4 & 5 & 6 & 7 & 8 \\
\hline 1 & + & - & + & + & - & - & + & - \\
\hline 2 & + & - & + & + & - & - & + & - \\
\hline 3 & + & - & + & + & - & - & + & - \\
\hline 4 & + & - & + & + & - & - & + & - \\
\hline 5 & + & - & - & - & + & - & + & - \\
\hline 6 & + & - & + & + & - & - & + & - \\
\hline 7 & + & - & + & + & - & - & + & - \\
\hline 8 & + & - & - & - & + & - & + & - \\
\hline 9 & + & - & + & + & - & - & + & - \\
\hline 10 & + & - & + & + & - & - & + & - \\
\hline 11 & + & - & + & + & - & - & + & - \\
\hline 12 & - & - & - & - & + & - & + & - \\
\hline 13 & - & - & + & - & + & - & + & - \\
\hline 14 & + & - & - & - & + & - & + & - \\
\hline 15 & + & - & + & + & - & - & + & - \\
\hline 16 & + & - & + & + & - & - & + & - \\
\hline 17 & + & - & + & + & - & - & + & - \\
\hline 18 & + & - & + & + & - & - & + & - \\
\hline 19 & + & - & + & - & + & - & + & - \\
\hline 20 & + & - & + & + & - & - & + & - \\
\hline 21 & + & - & + & + & - & - & + & - \\
\hline 22 & + & - & + & + & - & - & + & - \\
\hline 23 & - & - & - & + & + & - & + & - \\
\hline $24 *$ & + & - & + & + & - & - & + & - \\
\hline
\end{tabular}

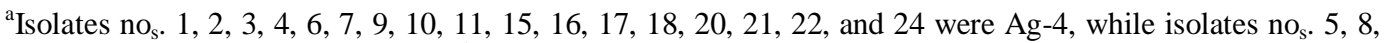
$12,13,14,19$, and 24 were AG-2. 'bigration distance of the protein fraction from the central well, which contained the antiserum. ${ }^{c}$ Protein fraction was present $(+)$ or absent $(-)$. *Homologous reaction.

\section{References}

Abe H, Baba T and Takauwa T 1969. Serological reaction of root-rot (Rhizoctonia solani) of sugar beets. Ann. Phytopathol. Soci. Japan 35: 374.

Adams GGM and Butler EE 1979. Serological relationships among anastomosis groups of Rhizoctonia solani. Phytopathol. 69: 629-633.

Agrios GN 2005. Plant Pathology. 5th Ed. Elsevier Academic Press, San Diego, California. pp. 384.

Bradford MM 1976. A rapid and sensitive method for the quantification of protein utilizing the principle of protein-dye binding. Anal. Biochem. 72: 248-254.

Guseva NN and Gromova BB 1982. Chemical and Biochemical Research Methods of Studying Plant Immunity. (In Russian). All-Union Institute of Plant Protection, Leningrad, U.S.S.R.

Hartman M 1996. Growing Flax: Diseases. The Flax Council of Canada.

Hussein EM, Aly AA, Ashour AZA and Nasr SM 1996. Cluster analysis of serological protein patterns of three Fusarium species. J. Agric. Sci. Mansoura Univ. 21: 3995-4012. 
Hussein EM 1992. Biochemical and serological studies for determining susceptibility of cotton cultivars to Fusarium oxysporum f.sp. vasinfectum. (In Russian). Ph.D. Thesis. All-Union Institute of Plant Protection, Leningrad, U.S.S.R.

Joseph FHJ, Anderson RE and Tatham RL 1992. Multivariable Data Analysis. Macmillan Publishing Company, New York. pp. 544.

Krylova TV 1981. Rhizoctoniosis of fiber flax. Mikologiya Fitopatol. 15: 511-513.

Ouchterlony O and Nilsson AL 1978. Immunodiffusion and Immunoelectrophoresis, P. 190. In "Handbook of Experimental Immunology (D.M. Weir, Ed.). 3rd Ed. Blackwell Scientific Publication, Oxford.

Rataj-Guranowska M, Wiatroszak I and Hornok L 1984. Serological comparison of two races of Fusarium oxysporum f.sp. lupine. Phytopath. Z. 110: 221-225.

Sokal JRR and Michener CD 1958. A statistical method for evaluating systematic relationships. Univ. Kansas Sci. Bull. 38: 1409-1438.

Watkins GM 1981. Compendium of Cotton Diseases. The American Phytopathological Society. St. Paul., Minnesota. pp. 87.

(Manuscript received on 19 March, 2014; revised on 10 March, 2015) 